Research Article

\title{
Launching Timing for Digital Products with Consumers' Variable Needs
}

\author{
Wei Li (iD) and Jia Liang \\ School of Business, Hebei University of Economics and Business, Shijiazhuang, China \\ Correspondence should be addressed to Wei Li; weilee@heuet.edu.cn
}

Received 30 July 2018; Revised 7 October 2018; Accepted 23 October 2018; Published 5 November 2018

Academic Editor: Neale R. Smith

Copyright (C) 2018 Wei Li and Jia Liang. This is an open access article distributed under the Creative Commons Attribution License, which permits unrestricted use, distribution, and reproduction in any medium, provided the original work is properly cited.

The value of a digital product diminishes because of the changing needs of consumers over time. To maintain the value of products, digital product firms sequentially launch upgraded versions of existing products. Therefore, a critical challenge faced by these firms is to determine the timing of launching upgrades. In this study, we develop an analytical model that incorporates needs variation and a product diffusion process in a sequential launching context. The comprehensive model considers two types of transition strategies (i.e., older generations are gradually phased out or totally replaced). We investigate the optimal launching timing of new product generation by conducting several computational experiments. Under total replacement, an astute manager will launch the upgrade when the existing version has reached the maturity stage. However, phase-out transition, the new upgrade, will be launched now or never according to the rate of needs variation. This study bridges the gap between the knowledge on the launching timing of digital products and the volatility of consumer valuation.

\section{Introduction}

The strategy of sequential launching (i.e., launching upgrades of an initial version sequentially) makes digital product vendors improve product features to catch up with the evolving needs of the market. For instance, consumers indicated the need to create PDF documents conveniently and quickly. Microsoft captured this need and launched MS Office 2010, which followed Office 2003/2007. MS Office 2010 enabled users to save their Word, Excel, and PowerPoint documents in PDF format. This example indicates that, through a series of launchings, digital product vendors improve product features to catch up with the evolving needs of the market.

Digital product firms adopting the strategy of successive launching face a trade-off in deciding the launching timing of the new generations. With the introduction of a new generation of product, digital product firms can meet emerging needs, and releasing new versions quickly enables digital product vendors to keep their products valuable to consumers. However, the introduction of a new version can cannibalize the sale of the former one. Consequently, new versions may affect the total revenue of firms with the decrease in cross-generation repeat purchases. Therefore, decisions of digital product firms on the timing of launching the new version can dramatically affect their profits from all product generations. Kalish and Lilien [1] imply that mistiming the introduction of a new product may lead to significant market loss for the digital product firm.

The firms' decision on launching timing should be based on the features of consumers' needs. Just as discussed above, the aim of launching new versions is to meet the evolving needs of consumers. Therefore, the remarkable feature of consumers' needs, variety, should be the decision basis of digital product vendors. The current study presents a novel model that can derive the optimal introduction timing for a new version of current software. This study comprehensively considers the variable needs of consumers and product diffusion dynamics with successive generations.

The current model is based on the Generalized Norton-Bass (GNB) model [2] and incorporates product depreciation caused by needs variation. To develop a holistic understanding of launching timing decisions involving successive upgrades, we consider two transition strategies, namely, total replacement and phase-out transition, as proposed by Jiang and Jain [3]. Numerical analysis illustrates that, under total replacement, the new version is optimal to the entry market 
when the sales of its former version reach the peak of sales. In the context of phase-out transition, upgrades are optimal to enter the market as soon as possible (when the rate of needs variation is low) or as late as possible (when the rate of needs variation is high). Our research sheds light on the decision problem of when to launch upgrades that can address the changing needs of consumers.

The rest of the paper is organized as follows. In Section 2, we present a survey of the literature in the market entry timing of new products. In Section 3, we develop a model to explore the problems on the launching timing of the new version with homogeneous consumers. In Section 4, we investigate the optimal new version launching policy of the digital product firm with a monopoly position. Here, we analyze the monopolist's optimal decisions in the two separate situations of total replacement and phase-out transition. In Section 5, we discuss the extensions of the model and report the results of the analysis. The results confirm the conclusions we obtain from Section 4. We also present additional insights from these extensions. Finally, in Section 6, we discuss the managerial implications of our model and point to possible future research.

\section{Related Literature}

Our study is closely related to the market entry strategy for new products, which is a long-standing research topic that has been studied in various streams of literature in new product development, marketing, and economics.

Prior work on this topic can be broadly classified into two categories. The first category focuses on consumers' valuation of the products. Lobel et al. [4] focus on optimizing the new product launches with strategic consumers. They demonstrate that the firms' profit would be different between the situations that the firms announce future release technologies and firms do not announce. Ebina et al. [5] investigate the product entry problem through a spatial competition model. Their work indicates that the leaders intend to locate closer to the center to delay the followers' product entry timing. Choudhary and Zhang [6] explore the launching timing of service in the context of software as a service (SaaS). They assert that the providers of SaaS should launch service earlier even though the service has many defects. However, the providers of on-premises software should launch product later and with less defects. Mehra et al. [7] capture the balance between costs and revenues of introducing an upgraded version. The balance results in increasing upgrade intervals through the product life cycle. Bhargava et al. [8] investigate the optimal launch timing of a new platform technology that connects two or more groups of users. The study shows that the early expansion of a product line of a new technology under a network effect is most optimal.

The second category of research considers the diffusion dynamics of existing products. Wilson and Norton [9] consider the entry timing for a product line extension with the assumption that the product extension has a lower profit margin than the current product. They suggest a "now or never" policy in which the line extension is best introduced as early as possible or not be introduced at all. Mahajan and Muller [10] relax Wilson and Norton's assumption of decreased profit margins for the new product. They claim that the introduction of a new product is optimal as soon as the product is available or when the sale of previous version nears its peak (they call this policy "now or at maturity"). Jiang and Jain [3] find that the optimal entry timing of the successive version can also lie between now and maturity. Joshi et al. [11] find that new products should be introduced to the market either before or after the peak sales of the existing product, depending on the leverage and backlash effect of the existing product. Krankel et al. [12] prove that introducing the new product generation is optimal when the technology of the existing generation is below a statedependent threshold. Existing literature focusing on product value does not consider diffusion dynamics. In turn, literature incorporating diffusion dynamics is silent on product value. The current research comprehensively considers both factors in determining the optimal launch timing of new product generations.

\section{Model}

We present a two-period model with a monopolist digital product firm denoted as $M$. Monopolist $M$ introduces digital product $V_{1}$ at the beginning of period $1\left(t_{1}\right)$ and digital product $V_{2}$ at the beginning of $\mathrm{t}$ period $2\left(t_{2} \geq t_{1}\right) . V_{2}$ is the upgraded version of $V_{1}$, which is similar to Windows 8 as the improved product generation of Windows 7 , and provides more functionalities to its users. Following the situation in Krankel et al. [12] and Mehra et al. [7], where the firm innovates based on the available technological frontier, we assume that both $V_{1}$ and $V_{2}$ are state of the art. This assumption is rational. In a perfect world, digital product firms, such as Microsoft, Oracle, and IBM, generally leverage all possible new opportunities to provide utility to consumers.

3.1. Utility of the Consumers and Price of the Products. The market consists of homogenous consumers. Inspired by the pioneering work of Mehra et al. [7], we define that each consumer in the homogeneous user market obtains instantaneous utility (see (1)) at time $t$ from $V_{i}(i=1,2)$ after the product is launched. $\theta$ is the instantaneous utility that consumers obtain from $V_{i}$ at the just time when the product is introduced. Inspired by Dou et al. [13], we assume that after $V_{i}$ has been introduced, instantaneous utility declines over time at a rate of $f(\alpha)$ due to product devaluation caused by the needs changes of consumers. $\alpha$ represents the variation rate of consumer needs. Function $f(\alpha)$ has properties of $f(\alpha)>$ 0 and $f^{\prime}(\alpha)>0$. Without loss of generality, we assume $f(\alpha)=k \alpha, k>0$. A significant difference between Mehra et al. [7] and the current study is that the former assumes that depreciation is caused by some objective factors, such as economic and technological obsolescence, whereas the latter focuses on the subjective factor, the consumers' needs.

$$
u_{i}(t)=\theta-f(\alpha) \cdot\left(t-t_{i}\right)
$$

In the theory of economics (e.g., [14]), utility represents the maximum price that the consumers are willing to pay 
for the product; and the difference between the consumers' utility and the actual price of the product is what to be called consumers' surplus. According to [14], the monopoly provider can price product to equal consumers' utility and then turn the gross consumers' surplus into its monopoly profit. Therefore, because of monopoly position in the market, $M$ can assign the price of $V_{i}$ (denoted as $\left.P_{i}(t)\right)$ to equal consumer utility defined in (1) and extract the consumers' full surplus.

$$
P_{i}(t)=u_{i}(t)
$$

3.2. Demand of the Products. We now turn to the instantaneous demand of each version. To obtain the demand of successive product generations, we need a multigenerational model to capture across-generation diffusion dynamics. By reviewing studies on multigenerational diffusion models, we find a viable approach in building upon the GNB model [2], which is mathematically consistent with the Norton and Bass model [15]. The GNB model can differentiate users that have already adopted an earlier generation from those who have not when counting the number of adopters substituting an old with a new generation. This feature makes the GNB model distinct from the Norton-Bass model. The noncumulative adoption rate for $V_{i}$ at time $t$ is denoted by $y_{i}$. Adopting the GNB model, $y_{i}$ takes the following form:

$$
\begin{aligned}
y_{1}(t)= & \begin{cases}m_{1} f_{1}(t) & t<t_{2}, \\
m_{1} f_{1}(t)\left[1-F_{2}\left(t-t_{2}\right)\right] & t \geq t_{2} .\end{cases} \\
y_{2}(t)= & {\left[m_{2}+m_{1} F_{1}(t)\right] f_{2}\left(t-t_{2}\right) } \\
& +m_{1} f_{1}(t) F_{2}\left(t-t_{2}\right) \quad t \geq t_{2} .
\end{aligned}
$$

In (3) and (4), $m_{i}$ represents the potential adopters that are unique to $V_{i}, F_{i}(t)$ is the cumulative number of adopters by time $t$ in period $i$, and $f_{i}(t)$ is the derivative of $F_{i}(t)$ and represents the diffusion rate of $V_{i}$ at time $t . F_{i}(t)$ and $f_{i}(t)$ describe the diffusion behavior of $V_{i}$ if $V_{i}$ is the only product in period $i$, and they are defined by Bass Model [16]. The parameters $p_{i}$ and $q_{i}$, respectively, represent the coefficient of innovation and imitation. The more the value of $p_{i}$ is, the more the consumers purchase the product initiatively; and the more the value of $q_{i}$ is, the more the consumers purchase the product following with the initiative buyers.

$$
\begin{aligned}
& F_{i}(t)= \begin{cases}0 & t<0, \\
\frac{1-e^{-\left(p_{i}+q_{i}\right) t}}{\left(q_{i} / p_{i}\right) e^{-\left(p_{i}+q_{i}\right) t}+1} & t \geq 0 .\end{cases} \\
& f_{i}(\mathrm{t})= \begin{cases}0, & t<0, \\
\frac{\left(p_{i}+q_{i}\right)^{2}}{p_{i}} \frac{1-e^{-\left(p_{i}+q_{i}\right) t}}{\left[\left(q_{i} / p_{i}\right) e^{-\left(p_{i}+q_{i}\right) t}+1\right]^{2}} & t \geq 0 .\end{cases}
\end{aligned}
$$

3.3. Profit of the Monopolist. To derive the total profit over the two periods, we need to understand the purchasing behavior of consumers. In the presence of successive product generations, the potential (or existing) adopters of an older generation can leapfrog (or switch) to a newer generation. Specifically, leapfrogging represents the behavior of potential adopters skipping previous generation(s) and directly adopting a newer generation. Switching represents the behavior of existing adopters of the previous generation making an upgrade to the new generation. The rates of leapfrogging and switching adoptions depend on the generation transition strategy adopted by the suppliers.

Some digital product firms discontinue the production and/or sale of the old generation as soon as a new generation is introduced. For example, Microsoft stops selling an older version as soon as an upgrade is launched. This generation transition strategy is known as total replacement [3]. Under total replacement, all potential adopters who adopted the older generation will leapfrog to the new generation after its introduction. Suppose that each consumer demands at most one unit of a specified version over the two periods, the instantaneous profit by time $t$ in period 1 is $P_{1}(t) m_{1} f_{1}(t)=$ $\left[\theta-\alpha\left(t-t_{1}\right)\right] m_{1} f_{1}(t)$, and instantaneous profit by time $t$ in period 2 is $P_{2}(t) y_{2}(t)=\left[\theta-\alpha\left(t-t_{2}\right)\right] y_{2}(t)$. Following with Jiang and Jain [3], we denote the planning horizon of $M$ as $T$, and the cumulative profit in each period is the integral of instantaneous profit. The decision problem faced by the monopolist is to maximize the total cumulative profit over two periods. The optimization model is derived as the following equations. To ease exposition, we ignore discounting in this section.

$$
\begin{array}{ll}
\max _{t_{2}} \pi & \\
& =\int_{t_{1}}^{t_{2}}\left[\theta-\alpha\left(t-t_{1}\right)\right] m_{1} f_{1}(t) d t \\
& +\int_{t_{2}}^{T}\left[\theta-\alpha\left(t-t_{2}\right)\right] y_{2}(t) d t \\
\text { s.t. } & t_{1} \leq t_{2} \leq T
\end{array}
$$

Some digital product vendors allow their old product generations to run their course on the market. For instance, the selling of Adobe Creative Suite 6 continues even after the launching of its successive version, Adobe Creative Cloud. This generation transition strategy is called phaseout transition [3]. As old and new generations coexist in the market, a portion of potential adopters will purchase $V_{1}$, rather than $V_{2}$, after $V_{2}$ has been introduced to the market in the phase-out transition. Therefore, instantaneous profit in period 2 becomes $P_{1}(t) m_{1} f_{1}(t)\left[1-F_{2}\left(t-t_{2}\right)\right]+P_{2}(t) y_{2}(t)$. The optimization model is obtained in the following equation (we also ignore discounting in the phase-out transition):

$$
\begin{aligned}
\max _{t_{2}} & \pi \\
& =\int_{t_{1}}^{t_{2}}\left[\theta-\alpha\left(t-t_{1}\right)\right] m_{1} f_{1}(t) d t
\end{aligned}
$$


TABLE 1: Settings of parameters or variables.

\begin{tabular}{lc}
\hline Parameters (variables) & Value \\
\hline$\alpha$ & $0.1,0.2,0.3,0.4,0.5,0.6,0.7,0.8,0.9$ \\
$T$ & $0.1,0.3,0.5,0.7,0.9$ \\
$\theta$ & 0.1 \\
$t_{1}$ & 0 \\
$t_{2}$ & {$[0, T]$} \\
$m_{1}=m_{2}$ & 1000 \\
$p_{1}=p_{2}$ & 0.0158 \\
$q_{1}=q_{2}$ & 0.0279 \\
\hline
\end{tabular}

$$
\begin{aligned}
& +\int_{t_{2}}^{T}\left[\theta-\alpha\left(t-t_{1}\right)\right] m_{1} f_{1}(t)\left[1-F_{2}\left(t-t_{2}\right)\right] d t \\
& +\int_{t_{2}}^{T}\left[\theta-\alpha\left(t-t_{2}\right)\right] y_{2}(t) d t
\end{aligned}
$$

$$
\text { s.t. } t_{1} \leq t_{2} \leq T
$$

What should be emphasized is that we ignore the production cost in the profit model (7) and (9), and it would not affect the validity of the current work. The production cost of digital product includes fixed cost and reproduction cost and has some special characteristics. Firstly, the reproduction cost of digital products is nearly zero [17]. For instance, when a mobile application is developed, the vendor could reproduce it by permitting consumers to download from app store. Second, the fixed cost of developing digital products is actually the sunk cost; and the prior literatures (e.g., [18]) have indicated that the sunk cost would not affect the optimal decision of the vendor. Therefore, to simplify the exposition, we ignore the production cost in the profit model. In academia, the existing work, such as [3], often ignores the production cost in their profit model, and the simplified model would not affect the analysis and conclusions of these works.

\section{Computational Study and Insights}

Our analysis focuses on the impact of needs variety on (1) the optimal launching timing of the new digital product version; (2) the total profit over two periods; and (3) the relationship between the optimal launching timing of the new version and the maturity timing of the old version. To investigate these three issues, we turn to the numerical method to conduct a sensitivity analysis of the parameter $\alpha$.

Optimization models are calculated using Matlab (a computational tool that is popularly used in academia). Without loss of generality, we set $m_{1}=m_{2}=1000, t_{1}=0$, $p_{1}=p_{2}=0.0158$, and $q_{1}=q_{2}=0.0279$. Existing studies (e.g., Norton and Bass 1987, Wilson and Norton 1989, Joshi et al. 2009, and Jiang and Jain 2012) adopt similar settings. Therefore, we have a better comparison with the previous studies. Table 1 presents all parameter settings or variables. The flow diagram of the Matlab program for a given rate of

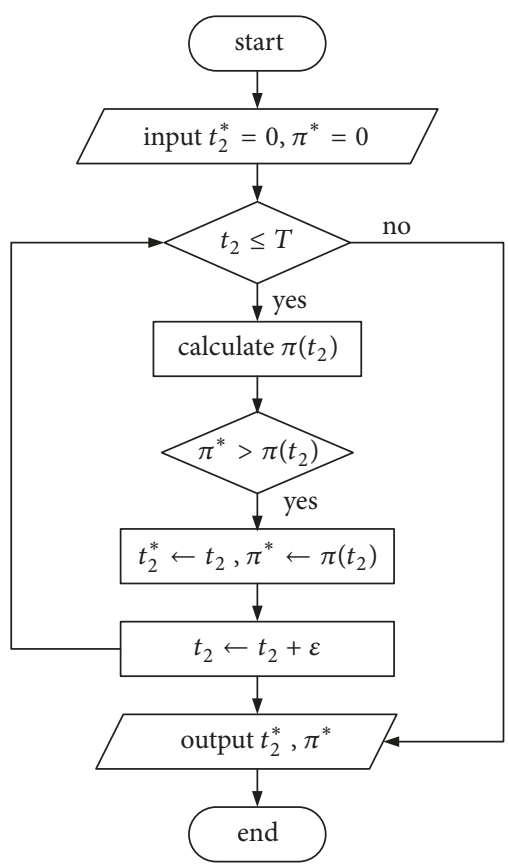

FIGURE 1: The flow diagram of the Matlab program.

needs variation is described in Figure 1 (the parameter $\varepsilon$ is the step). All the experiments in the current work are conducted using the algorithm described in Figure 1.

4.1. The Impact of Needs Variation under Total Replacement. On the basis of the results of numerical experiments, we plot the behavior of optimal launching timing of the new product and the maximum total profit in respect of the rate of needs variation (Figure 2). For simplicity, we denote $t_{2}^{*}$ as the optimal launching timing of $V_{2}, \pi^{*}$ as the maximum of total profit, and $\widehat{t}_{1}$ as the timing when the noncumulative diffusion rate of $V_{1}$ reaches the peak. We now describe the results of the sensitivity analysis as follows.

Observation 1. In the situation of total replacement, (I) $t_{2}^{*}$ nearly equals $\widehat{t}_{1}\left(t_{2}^{*}-\widehat{t}_{1} \approx 0\right)$ and increases in $\alpha$. (II) $\pi^{*}$ decreases with the increase of $\alpha$; moreover, the decreasing speed positively relates to planning horizon.

In the situation of total replacement, the launching timing of the new version increases with the needs variation. In such a situation, the monopolist prolongs the sales timing of the old product, and it makes the old product contribute more to the firm's margin before it quits the market. Needs variation, which leads to product depreciation, appears to strengthen this inclination because digital product firms want to make up for the loss resulting from product depreciation. In addition, for the same level of needs variation, the launching timing of the new version increases with the firm's planning horizon. The intrinsic reason is easy to understand. When the planning horizon becomes longer, the sales period of each version is extended accordingly.

From (2), the existing product's noncumulative diffusion rate declines after the timing when it arrives at its peak. The 


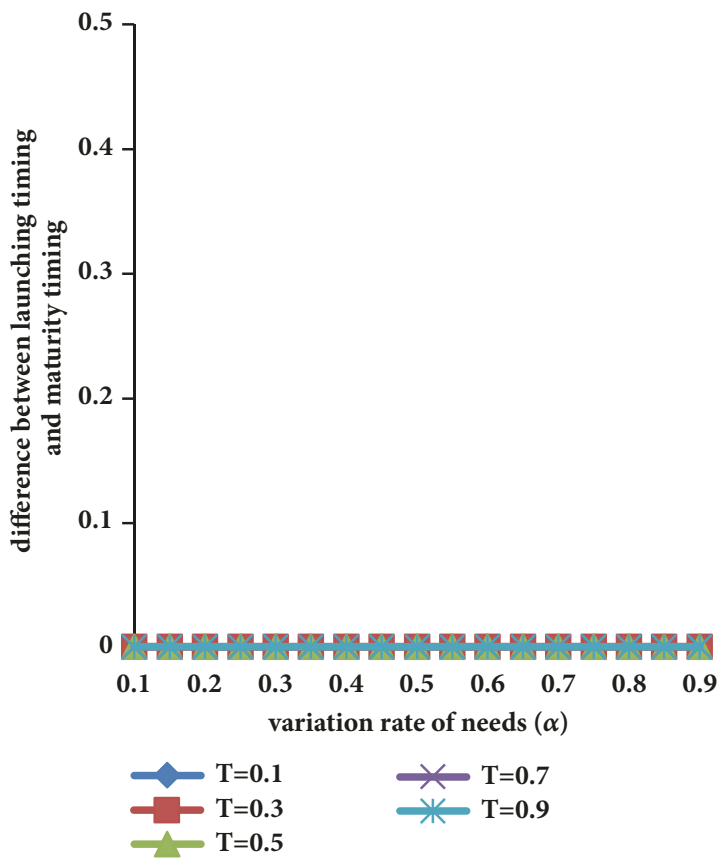

(a) Impact of $\alpha$ on $t_{2}^{*}-\widehat{t}_{1}$

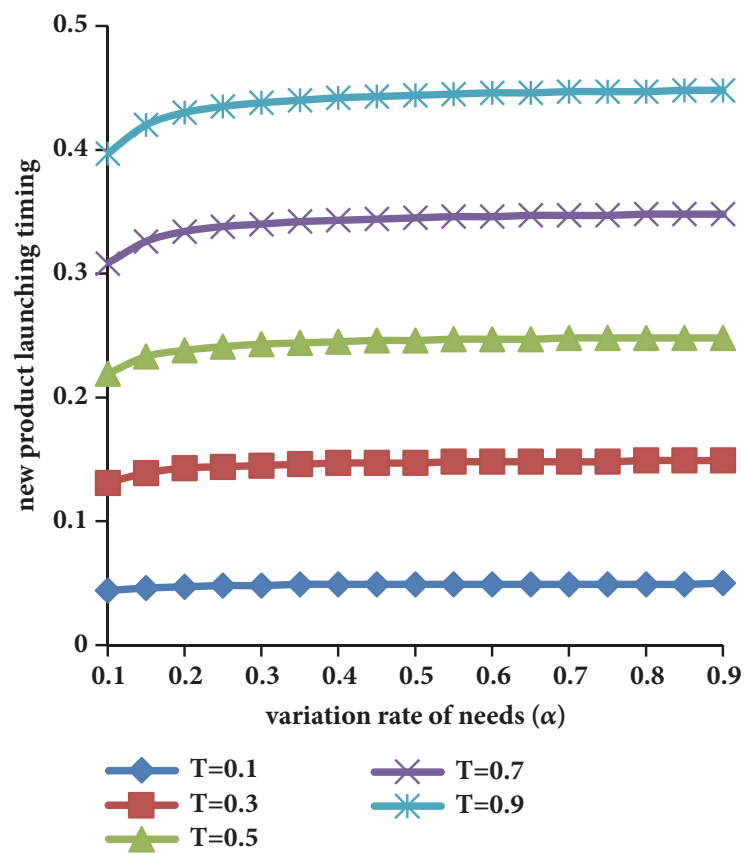

(b) Impact of $\alpha$ on launching timing $t_{2}^{*}$

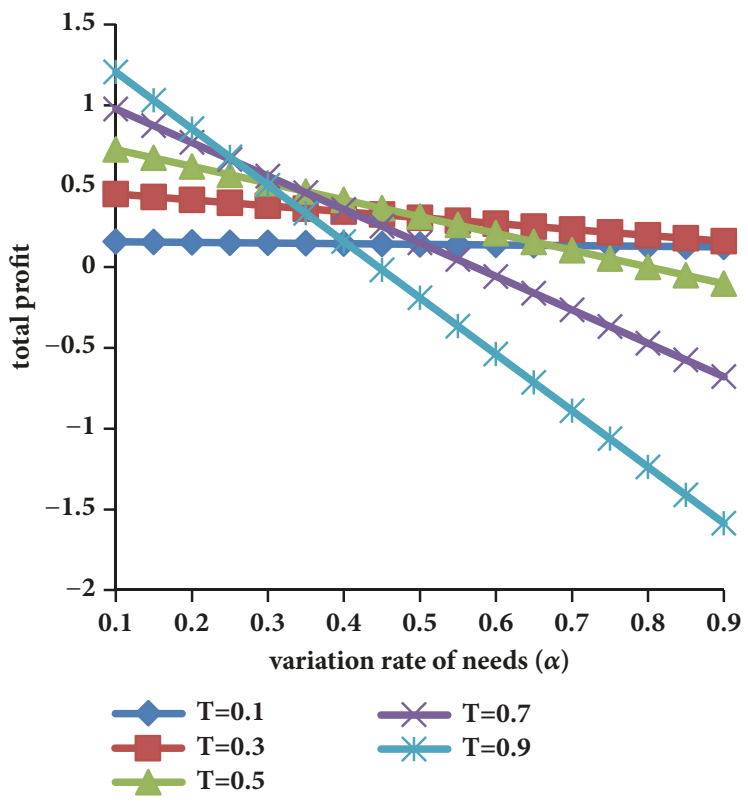

(c) Impact of $\alpha$ on total profit $\pi^{*}$

Figure 2

decline of the diffusion rate results in the shrinking of profit margin contributed by the existing product. Therefore, the digital product vendor tends to provide the new version when the marketing of an existing product reaches maturity. In this way, the digital product vendor can increase market coverage continuously by providing a new version with better features.

Moreover, the optimality of the digital product firm's profit decreases with respect to increases in the needs variation. A faster change of needs makes the consumers devalue the digital products more, and it forces the firm to reduce prices and suffer losses from the low sales performance. In addition, when the needs uncertainty is lower, the value of the digital product maintains a relatively high level. In this scenario, the digital product vendor can benefit from higher prices during longer planning horizon. However, when the needs variety is sufficiently high, the rate of product depreciation becomes sharper. In this scenario, the prices become even lower during longer planning horizon, resulting in a worse profit performance than that in the case of shorter planning horizon. 


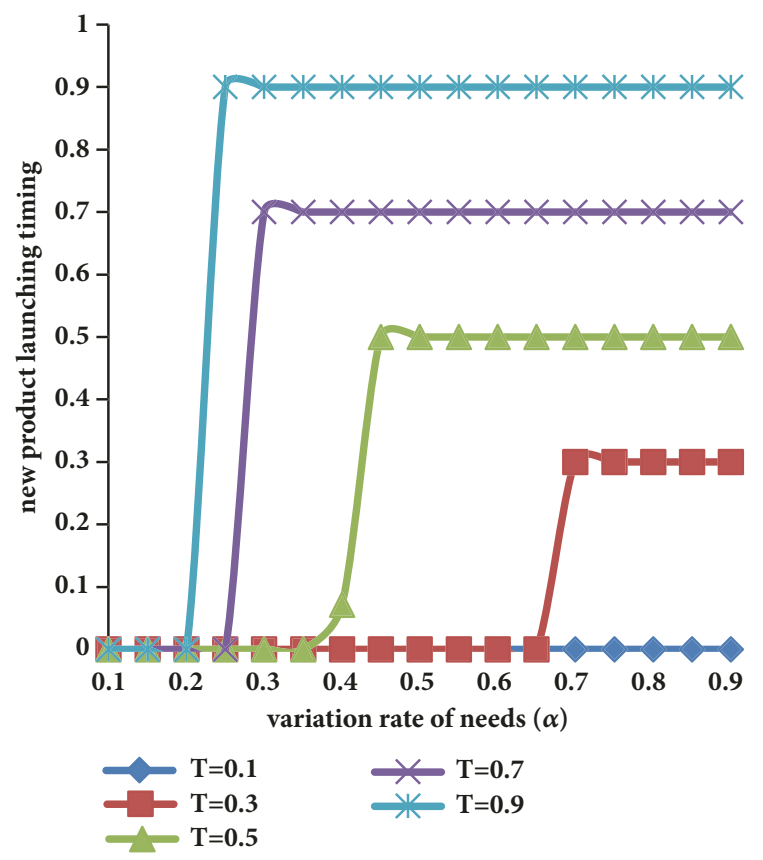

(a) Impact of $\alpha$ on $t_{2}^{*}$

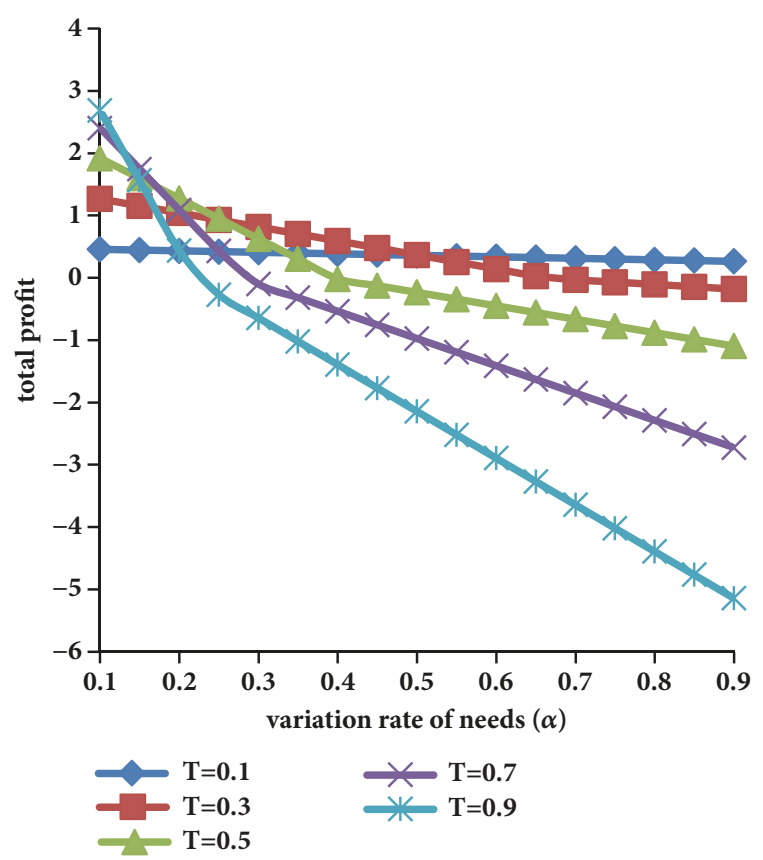

(b) Impact of $\alpha$ on $\pi^{*}$

FiguRE 3

4.2. The Impact of Needs Variation under Phase-Out Transition. If the digital product vendor adopts the strategy of phase-out transition when he launches the new version, the impact of needs variation on $t_{2}^{*}$ and $\pi^{*}$ will be different from that in the context of total replacement. The impact of needs variation is illustrated in Figure 3 and established analytically in Observation 2.

Observation 2. In the situations of phase-out transition, (I) if $\alpha$ is sufficiently low, $V_{2}$ should be introduced to the market as soon as possible. However, if $\alpha$ is sufficiently high, $V_{2}$ should be introduced to the market as late as possible. The threshold of $\alpha$ beyond which the digital product firm changes its launching policy declines with the growth of planning horizon. (II) $\pi^{*}$ decreases in respect of the growth of $\alpha$, and the decreasing rate positively relates to planning horizon.

In the situation of phase-out transition, $V_{1}$ is still on sale after $V_{2}$ has been launched. The introduction of $V_{2}$ expands the product line and enlarges potential consumers. However, releasing $V_{2}$ also cannibalizes the profit margin of $V_{1}$. The reason is that after $V_{2}$ becomes available, a portion of the potential consumers of $V_{1}$, who would have purchased $V_{1}$ if it were the only digital product available, would leapfrog to $V_{2}$. According to Jiang and Jain (2012), the number of leapfrogging adoptions during a small time interval $[t-\lambda, t]$ can be expressed as $m_{1}\left[F_{1}(t)-F_{1}(t-\lambda)\right] F_{2}\left(t-t_{2}\right)$. Considering the positive and negative effects of releasing $V_{2}$, the digital product firm faces the problem of a trade-off between these two opposite effects.

When the rate of needs variation is low, digital products suffer relatively low depreciation. In this case, the digital product vendor is able to maintain a relatively higher price of products. When the provider introduces $V_{2}$ to the market, the lower needs uncertainty permits the charging of higher prices for both $V_{1}$ and $V_{2}$. At this point, the positive effect of releasing $V_{2}$ (enlarging the firm's potential consumers) exceeds the negative one (cannibalizing the margin of $V_{1}$ ). Therefore, the introduction of $V_{2}$ as soon as possible under a relatively slower needs variation is optimal.

In comparison, when the needs variation is faster, the digital products in the market suffer sharper depreciation. In this context, the digital product vendor has to continue to reduce the price of $V_{2}$ after it has been launched. Under such a scenario, $V_{2}$ cannibalizes the profit margin of $V_{1}$, but it is less helpful in expanding the market coverage of the provider. In other words, the negative effect of releasing $V_{2}$ surpasses the positive one. Therefore, the digital product vendor should delay releasing $V_{2}$ as much as possible when facing higher needs uncertainty.

The needs variation also has a negative effect on the profit of the digital product vendor. The needs variation disables the digital product to meet consumer needs, which in turn devalue the digital products. The digital product firm has to reduce prices in both periods because of product depreciation, and this move harms profit. In addition, if the rate of needs variation is low, profit is optimal for the digital product vendor during the long-horizon plan (Figure 3(b)). However, if the rate of needs variation is higher, the digital product vendor should limit its planning horizon to a shorter period.

\section{Extensions}

In this section, we describe several model extensions and show that the main insights from our basic model remain unchanged. 
5.1. Discounting. We now investigate the effects of discounting as a factor on the launching timing of $V_{2}$ and the total profit. For simplicity, we assume that the consumers and the digital product vendor face a common discount factor $e^{-\delta t}$, where $\delta(0 \leq \delta \leq 1)$ is the rate of continuous discount. In consideration of the discount factor, the consumer instantaneous utility $u_{i}^{D}(t)$ has evolved into (11). In addition, the product price at time $\left.t, P_{i}^{D}(t)\right)$, equals the consumers' instantaneous utility.

$$
\begin{aligned}
& u_{i}^{D}(t)=e^{-\delta t}\left[\theta-f(\alpha) \cdot\left(t-t_{i}\right)\right] \\
& P_{i}^{D}(t)=u_{i}^{D}(t)
\end{aligned}
$$

We now explore the problem of determining new product launching timing under total replacement. If discounting is considered, the instantaneous profit of period 1 becomes $e^{-\delta\left(t-t_{1}\right)} P_{1}^{D}(t) m_{1} f_{1}(t)=e^{-2 \delta\left(t-t_{1}\right)}[\theta-f(\alpha) \cdot(t-$ $\left.\left.t_{1}\right)\right] m_{1} f_{1}(t)$, and the instantaneous profit of period 2 becomes $e^{-\delta\left(t-t_{1}\right)} P_{2}^{D}(t) y_{2}(t)=e^{-2 \delta\left(t-t_{1}\right)}\left[\theta-f(\alpha) \cdot\left(t-t_{2}\right)\right] y_{2}(t)$. According to the instantaneous profit of the two periods, the digital product vendor's decision problem in such a situation can be redefined as follows:

$$
\begin{aligned}
\max _{t_{2}} & \pi \\
& =\int_{t_{1}}^{t_{2}} e^{-2 \delta\left(t-t_{1}\right)}\left[\theta-\alpha\left(t-t_{1}\right)\right] m_{1} f_{1}(t) d t
\end{aligned}
$$

$$
+\int_{t_{2}}^{T} e^{-2 \delta\left(t-t_{1}\right)}\left[\theta-\alpha\left(t-t_{2}\right)\right] y_{2}(t) d t
$$

$$
\text { s.t. } t_{1} \leq t_{2} \leq T
$$

The optimization problem is solved in a numerical experiment. The experiment aims at investigating the optimal introduction policy under needs uncertainty by considering the discounting factor. Parameter $\delta$ is set to $0.1,0.3,0.5,0.7$, and 0.9 , and the settings of other parameters are the same as those indicated in Table 1.

We use the algorithm illustrated in Figure 1 to solve the optimization model in (13). We plot the results of the numerical experiments in Figure 4, and these results are summarized as follows.

Observation 3. In the situation of total replacement, (I) $t_{2}^{*}$ nearly equals $\widehat{t}_{1}$ and increases with the growth of $\alpha$; (II) $\pi^{*}$ decreases with the increase of $\alpha$, and the decreasing rate is negatively related to discounting factor.

In phase-out transition, the instantaneous profit of period 1, which considers discounting, transforms into $e^{-\delta\left(t-t_{1}\right)} P_{1}^{D}(t) m_{1} f_{1}(t)$ that equals $e^{-2 \delta\left(t-t_{1}\right)}[\theta-\alpha(t-$ $\left.\left.t_{1}\right)\right] m_{1} f_{1}(t)$. The instantaneous profit of period 2 transforms into $e^{-\delta\left(t-t_{1}\right)} P_{1}^{D}(t) m_{1} f_{1}(t)\left[1-F_{2}\left(t-t_{2}\right)\right]+e^{-\delta\left(t-t_{1}\right)} P_{2}^{D}(t) y_{2}(t)$ that equals $e^{-2 \delta\left(t-t_{1}\right)}\left[\theta-\alpha\left(t-t_{1}\right)\right] m_{1} f_{1}(t)\left[1-F_{2}\left(t-t_{2}\right)\right]+$ $e^{-2 \delta\left(t-t_{1}\right)}\left[\theta-\alpha\left(t-t_{2}\right)\right] y_{2}(t)$. According to the instantaneous profit of both periods, the determination problem of the digital product firm can be formulated as follows:

$$
\begin{aligned}
\max _{t_{2}} & \pi \\
= & \int_{t_{1}}^{t_{2}} e^{-2 \delta\left(t-t_{1}\right)}\left[\theta-\alpha\left(t-t_{1}\right)\right] m_{1} f_{1}(t) d t+\int_{t_{2}}^{T} e^{-2 \delta\left(t-t_{1}\right)}\left[\theta-\alpha\left(t-t_{1}\right)\right] m_{1} f_{1}(t)\left[1-F_{2}\left(t-t_{2}\right)\right] d t \\
& +\int_{t_{2}}^{T} e^{-2 \delta\left(t-t_{1}\right)}\left[\theta-\alpha\left(t-t_{2}\right)\right] y_{2}(t) d t
\end{aligned}
$$$$
\text { s.t. } \quad t_{1} \leq t_{2} \leq T
$$

To examine the optimum product launching policy, we calculate the proposed model in (15) through the algorithm described in Figure 1. The main results are presented in Figure 5 and summarized below.

Observation 4. In the situations of phase-out transition, (I) if $\alpha$ is sufficiently low, $V_{2}$ should be introduced to the market as soon as possible. However, if $\alpha$ is sufficiently high, $V_{2}$ should be introduced to the market as late as possible. (II) $\pi^{*}$ decreases in respect of the growth of $\alpha$; moreover, the decrease rate of $\pi^{*}$ negatively relates to discounting.

5.2. Improvements of the New Version in Features. The model in Section 3 assumes that the digital products in each period provide the same utility to consumers at the punctual time the products are adopted. However, the new version often provides more utility to consumers than its former product version, as the new version usually has more features than the former one. For example, the operating system product Windows 8 adopted a Metro interface that is different from the former Windows product family. By considering better features offered by the new version, we extend the model presented in Section 3 to incorporate the improvement of the new version into the features.

We define an improvement coefficient $\gamma$ to measure the improvement degree of $V_{2}$ in its features. Therefore, the instantaneous utility at time $t$ offered by $V_{2}$ (denoted as $u_{2}^{F I}(t)$ ) becomes $(1+\gamma) \theta-\alpha\left(t-t_{2}\right)$. The instantaneous utility provided by $V_{1}$ (denoted as $\left.u_{1}^{F I}(t)\right)$ still equals $\theta-\alpha t$. The instantaneous price of version $i, P_{i}^{F I}(t)$, equals the utility it can provide at the same time, i.e., $P_{i}^{F I}(t)=u_{i}^{F I}(t)$.

Next, we investigate the optimum launching policy of the new version in the situation of total replacement. Based on 


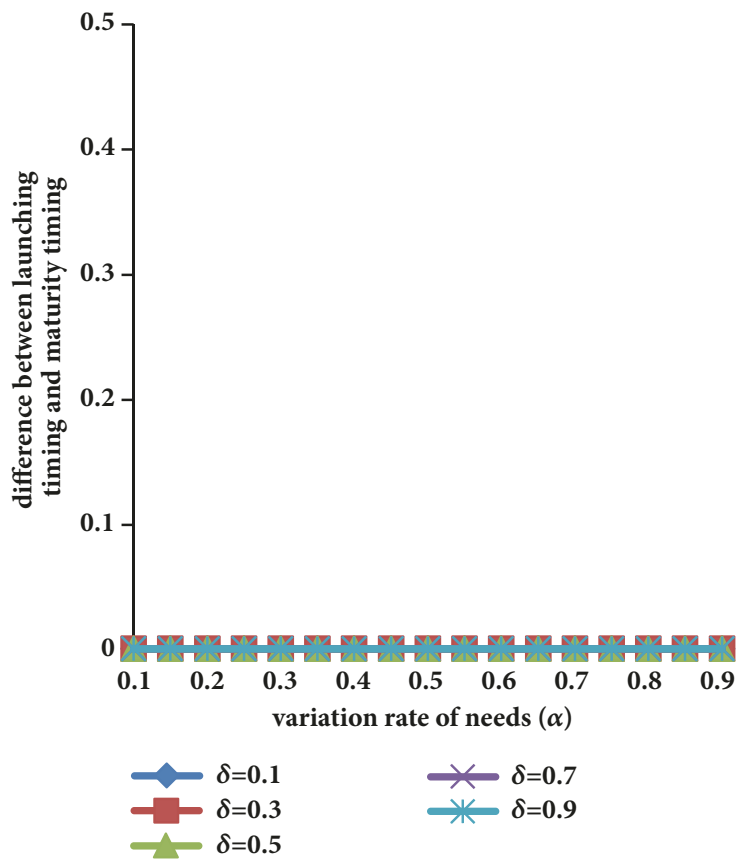

(a) Impact of $\alpha$ on $t_{2}^{*}-\widehat{t}_{1}$

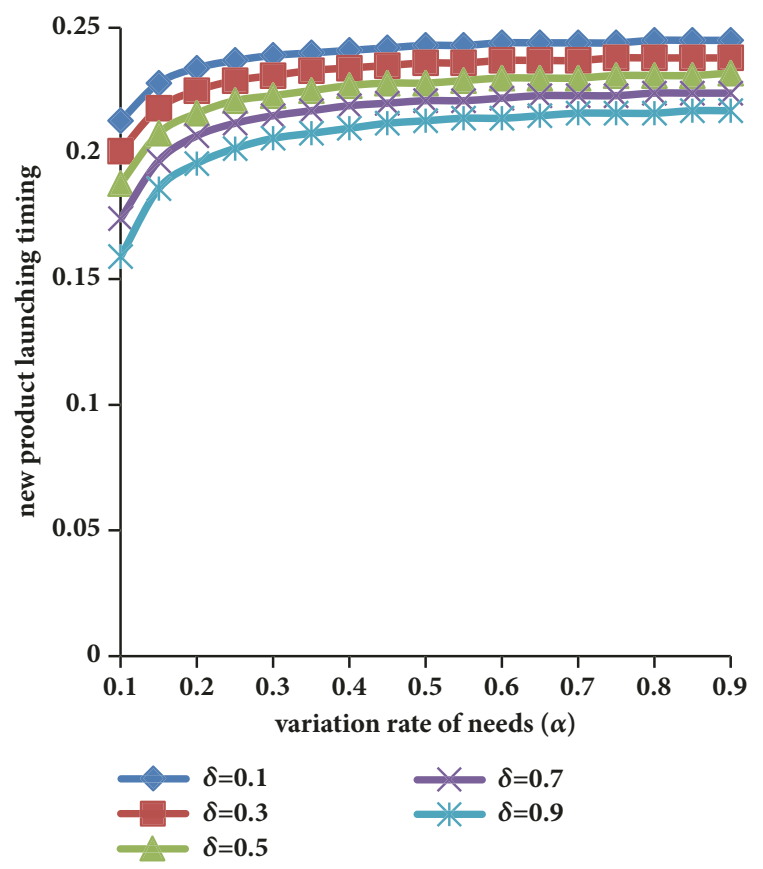

(b) Impact of $\alpha$ on $t_{2}^{*}$

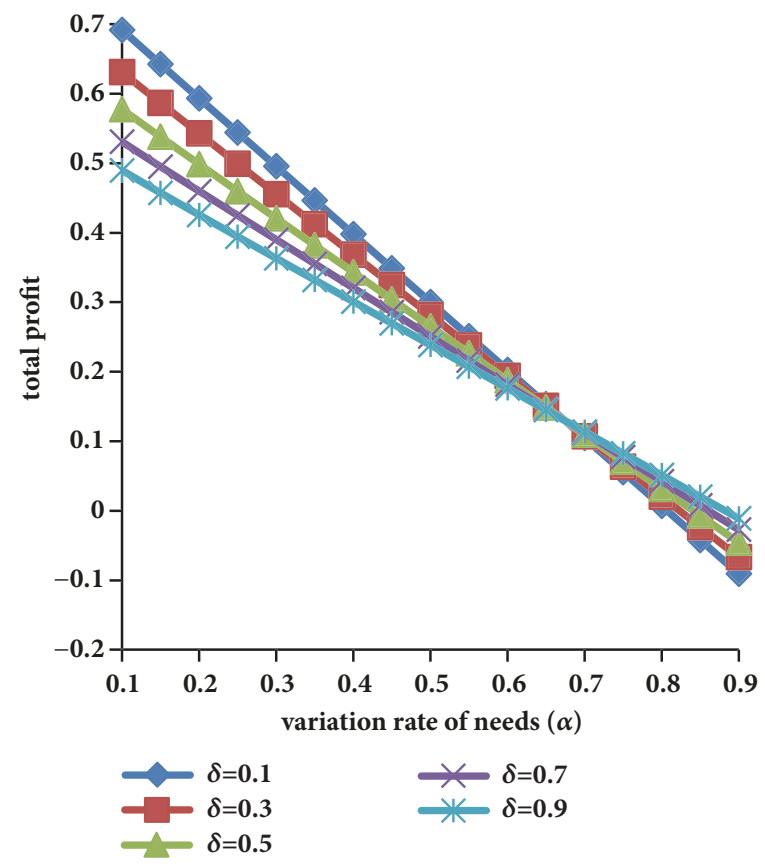

(c) Impact of $\alpha$ on $\pi^{*}$

FIGURE 4

the instantaneous price of both versions, instantaneous profit in the two periods, respectively, equals $(\theta-\alpha t) m_{1} f_{1}(t)$ and $\left[(1+\gamma) \theta-\alpha\left(t-t_{2}\right)\right] y_{2}(t)$. Therefore, the digital product firm's problem in deciding on the optimal market launching time for $V_{2}$ is formulated in (17).

$$
\begin{aligned}
= & \int_{t_{1}}^{t_{2}}(\theta-\alpha t) m_{1} f_{1}(t) d t \\
& +\int_{t_{2}}^{T}\left[(1+\gamma) \theta-\alpha\left(t-t_{2}\right)\right] y_{2}(t) d t
\end{aligned}
$$

s.t. $t_{1} \leq t_{2} \leq T$ 


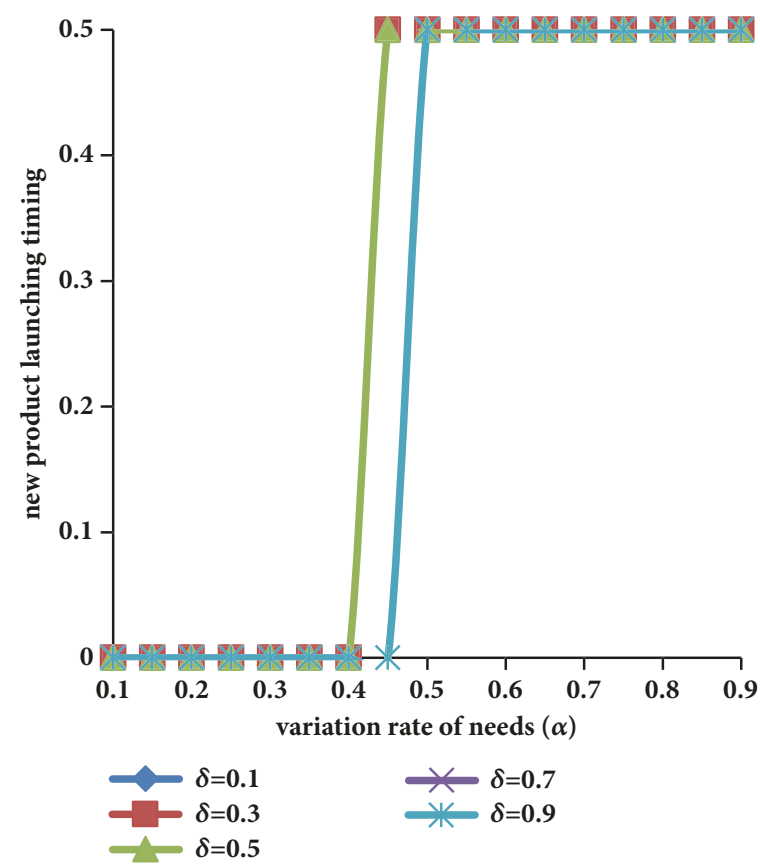

(a) Impact of $\alpha$ on $t_{2}^{*}$

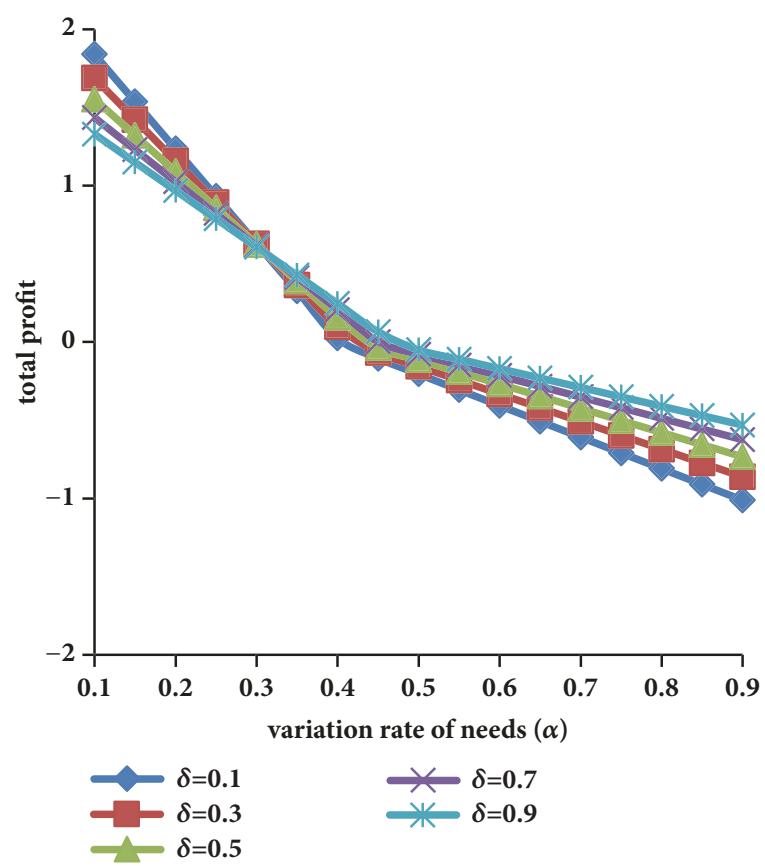

(b) impact of $\alpha$ on $\pi^{*}$

Figure 5

We conduct numerical experiments to solve the decision problem. We set the value of parameter $\gamma$ to $0.1,0.3,0.5,0.7$, and 0.9 , and the values of the other parameters are as the same as those indicated in Table 1. The main results of the experiment are illustrated in Figure 6, and these results are summarized as follows.

Observation 5. In the situation of total replacement, (I) $t_{2}^{*}$ nearly equals $\widehat{t}_{1}$ and increases with the growth of $\alpha$; (II) $\pi^{*}$ decreases with the increase of $\alpha$; (III) $t_{2}^{*}$ negatively relates to parameter $\gamma$, whereas $\pi^{*}$ positively relates to $\gamma$.

Now turn to phase-out transition; we explore the optimal launching timing for $V_{2}$ in such a situation. In consideration of the feature improvements of $V_{2}$, the instantaneous profit in period 2 evolves into $(\theta-\alpha t) m_{1} f_{1}(t)\left[1-F_{2}\left(t-t_{2}\right)\right]+$ $\left[(1+\gamma) \theta-\alpha\left(t-t_{2}\right)\right] y_{2}(t)$, and instantaneous profit in period 1 still equals $(\theta-\alpha t) m_{1} f_{1}(t)$. Therefore, the digital product vendor's decision problem about the launching timing for $V_{2}$ is specified in (19).

$$
\begin{aligned}
\max _{t_{2}} & \pi \\
= & \int_{t_{1}}^{t_{2}}(\theta-\alpha t) m_{1} f_{1}(t) d t \\
& +\int_{t_{2}}^{T}(\theta-\alpha t) m_{1} f_{1}(t)\left[1-F_{2}\left(t-t_{2}\right)\right] d t \\
& +\int_{t_{2}}^{T}\left[(1+\gamma) \theta-\alpha\left(t-t_{2}\right)\right] y_{2}(t) d t
\end{aligned}
$$

s.t. $\quad t_{1} \leq t_{2} \leq T$
The optimization model in (19) is solved with numerical experiments, and the findings are shown in Figure 7. We summarize the findings as follows.

Observation 6. In the situations of phase-out transition, (I) $V_{2}$ should be introduced to the market as soon as possible when $\alpha$ is sufficiently low, and as late as possible when $\alpha$ is sufficiently high. (II) The threshold of $\alpha$ beyond which the digital product vendor changes its introduction policy increase with the parameter $\gamma$. (III) $\pi^{*}$ decreases in respect of the growth of $\alpha$, and the decreasing rate positively relates to $\gamma$.

5.3. Increasing Potential Consumers. In this section, we augment the model developed in Section 3 by considering a continuous increase of potential consumers. This extension enables us to capture the more realistic context. For example, the revenue of Microsoft nearly continues to increase in each fiscal year (see Microsoft Annual Report 2017. http:// www.microsoft.com/investor/reports/arl7/index.html), and this fact implies that new product/service generations (e.g., new versions of Windows operating systems, Office Package, and better performance of cloud services) are usually more attractive. We define $\eta$ as the increasing rate of consumers in period 2, and the potential adopter in period $2, m_{2}$, is $(1+\eta) m_{1}$. Taking the increasing rate of consumers size into account, the noncumulative adoption rate for $V_{2}, y_{2}^{I}$ is formulated as follows.

$$
\begin{aligned}
y_{2}^{I}(t)= & {\left[(1+\eta) m_{1}+m_{1} F_{1}(t)\right] f_{2}\left(t-t_{2}\right) } \\
& +m_{1} f_{1}(t) F_{2}\left(t-t_{2}\right) \quad t \geq t_{2} .
\end{aligned}
$$




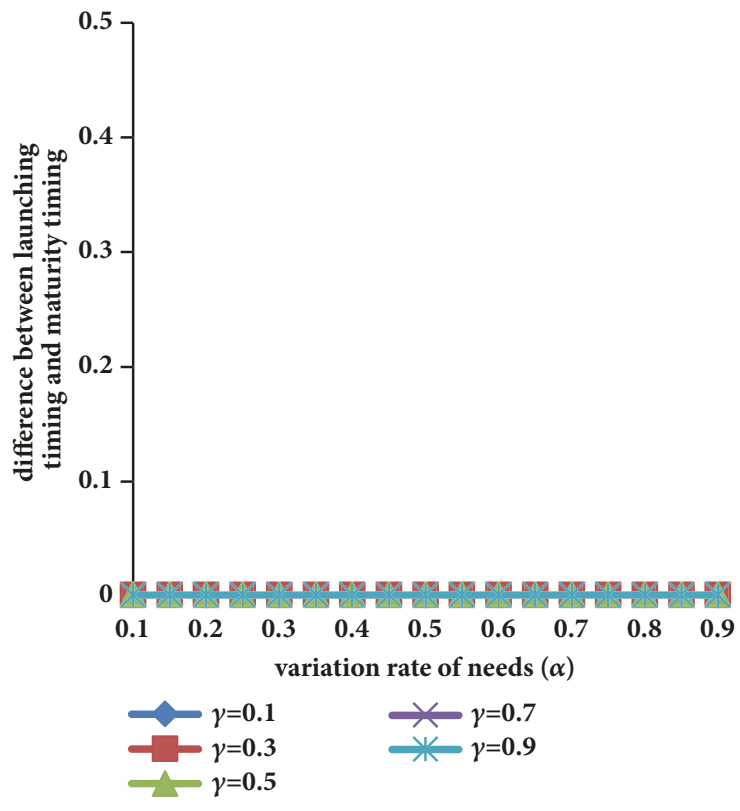

(a) Impact of $\alpha$ on $t_{2}^{*}-\widehat{t}_{1}$

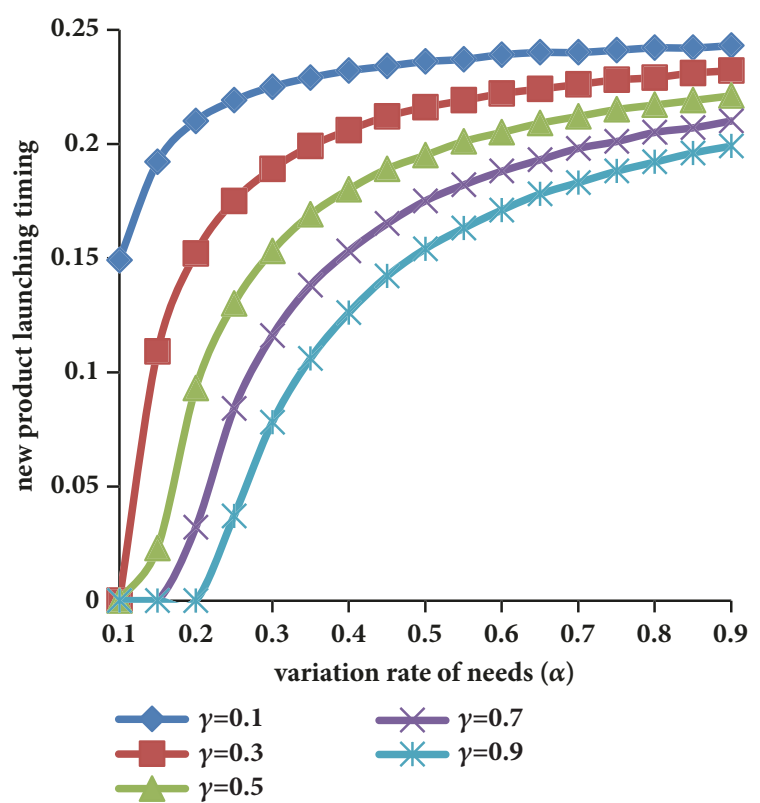

(b) Impact of $\alpha$ on $t_{2}^{*}$

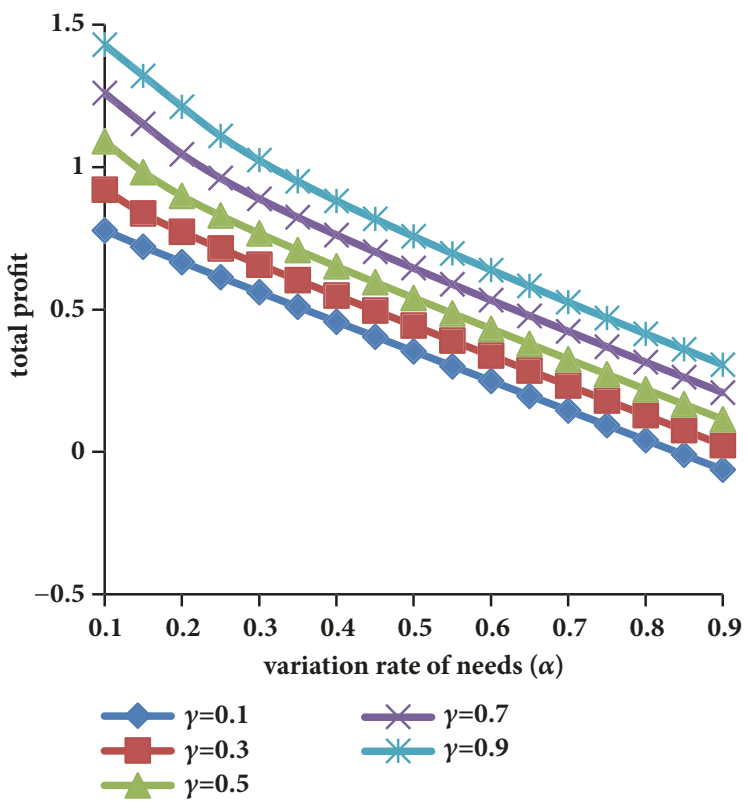

(c) Impact of $\alpha$ on $\pi^{*}$

Figure 6

In the scenario of total replacement, the instantaneous profit in period 1 is $(\theta-\alpha t) m_{1} f_{1}(t)$, which is the same as that in Section 3. However, taking the increase of market size into account, the instantaneous profit in period 2 evolves into $\left[\theta-\alpha\left(t-t_{2}\right)\right] y_{2}^{I}(t)$. Thus, the market entry timing problem faced by the monopolist evolves into (22).

$$
\begin{aligned}
\max _{t_{2}} & \pi \\
& =\int_{t_{1}}^{t_{2}}(\theta-\alpha t) m_{1} f_{1}(t) d t
\end{aligned}
$$

$$
+\int_{t_{2}}^{T}\left[\theta-\alpha\left(t-t_{2}\right)\right] y_{2}^{I}(t) d t
$$

s.t. $t_{1} \leq t_{2} \leq T$

The problem is solved with numerical experiments. We set the value of parameter $\eta$ to $0.1,0.3,0.5,0.7$, and 0.9 , and the settings of other parameters are the same as those presented in Table 1. We plot the numerical results in Figure 8, and the results are presented as follows. 


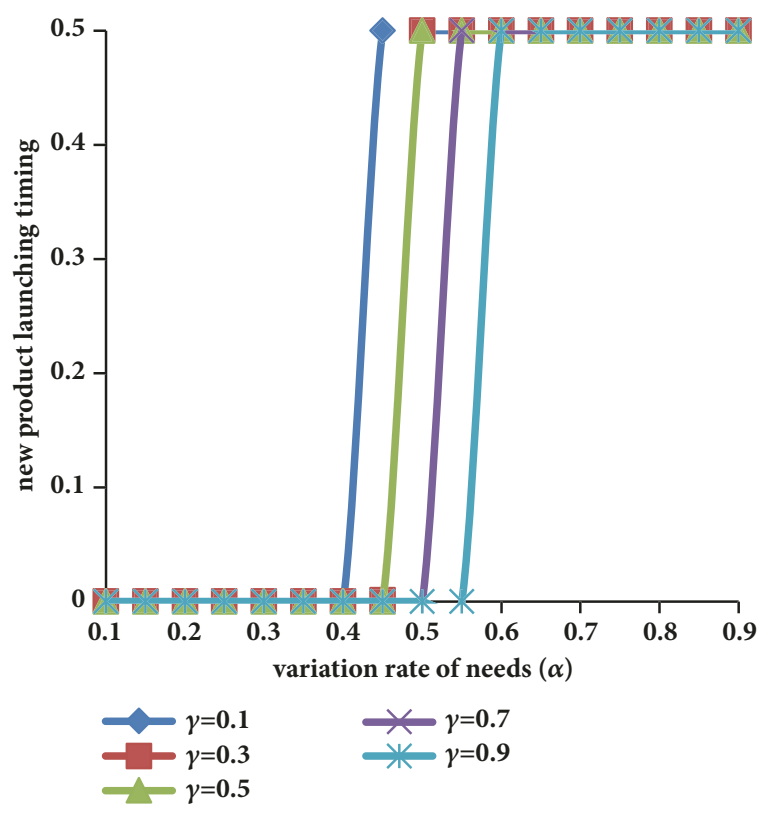

(a) Impact of $\alpha$ on $t_{2}^{*}$

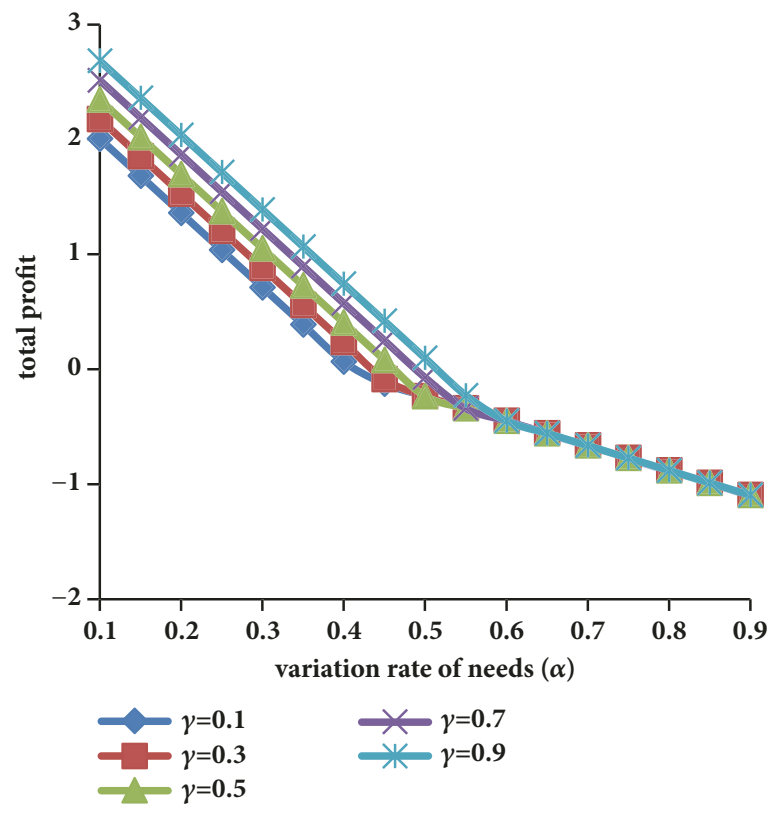

(b) Impact of $\alpha$ on $\pi^{*}$

Figure 7

Observation 7. In the situation of total replacement, (I) $t_{2}^{*}$ nearly equals $\hat{t}_{1}$ and increases with the growth of $\alpha$; moreover, the increase rate positively relates to $\eta$; (II) $\pi^{*}$ decreases with the increase of $\alpha$, and the decrease rate positively relates to $\eta$.

We next investigate the problem of new product launching timing in phase-out transition. The digital product vendor's instantaneous profit in period 1 remains equal to $(\theta-\alpha t) m_{1} f_{1}(t)$. However, the firm's instantaneous profit in period 2, by incorporating the increase in potential market size, transforms into $(\theta-\alpha t) m_{1} f_{1}(t)\left[1-F_{2}\left(t-t_{2}\right)\right]+[\theta-\alpha(t-$ $\left.\left.t_{2}\right)\right] y_{2}^{I}(t)$. Therefore, we can obtain the optimization model on the digital product vendor's decision problem through (24).

$$
\begin{aligned}
\max _{t_{2}} \pi & \\
= & \int_{t_{1}}^{t_{2}}(\theta-\alpha t) m_{1} f_{1}(t) d t \\
& +\int_{t_{2}}^{T}(\theta-\alpha t) m_{1} f_{1}(t)\left[1-F_{2}\left(t-t_{2}\right)\right] d t \\
& +\int_{t_{2}}^{T}\left[\theta-\alpha\left(t-t_{2}\right)\right] y_{2}^{I}(t) d t
\end{aligned}
$$

$$
\text { s.t. } t_{1} \leq t_{2} \leq T
$$

The optimization model is solved with a numerical method. The numerical results are illustrated in Figure 9 and summarized as follows.

Observation 8. In the situations of phase-out transition, (I) $V_{2}$ should be launched as soon as possible when $\alpha$ is sufficiently low, and as late as possible when $\alpha$ is sufficiently high. The threshold of $\alpha$ beyond which the digital product vendor changes its introducing behavior negatively relates to $\eta$. (II) $\pi^{*}$ decreases in respect of the growth of $\alpha$, and the decreasing rate positively relates to $\eta$.

\section{Conclusion}

6.1. Managerial Insights. The successive launching of digital products is a complex task, and the timing of launching a new version is one of the most difficult decisions a manager must make. The evolvement of consumer needs drives the decision to issue a product generation. We build an analytical model driven solely by economic considerations to study this decision problem. We conduct numerical experiments to solve the analytical model under the condition that consumers are homogeneous in their utility from the product. The numerical results indicate that, under total replacement, the digital product firm will introduce a new version when the former version has reached its maturity stage. However, under phaseout transition, the new version will be introduced now or never, depending on the rate of needs variation. The key conclusions of this paper are summarized in Figure 10.

6.2. Future Research. Our study captures the impact of the needs variation associated with discounting, product features, and market growth rate on the optimal launching timing of new versions. Nevertheless, our study also has its limitations.

First, the study assumes that the market consists of homogeneous consumers in terms of their evaluation of product features. A challenging extension is to jointly consider consumer heterogeneity and needs uncertainty. Moreover, the 


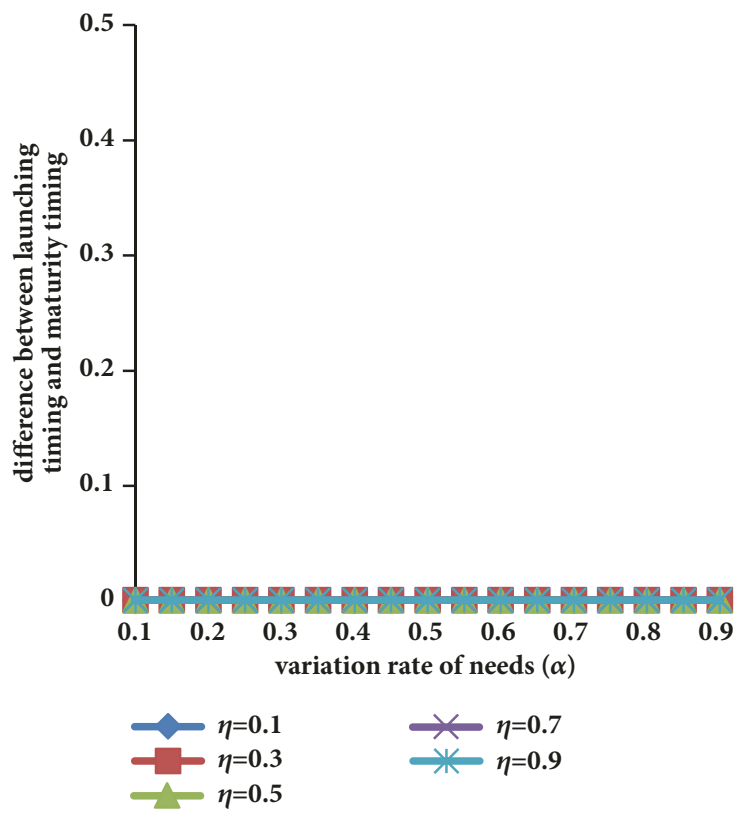

(a) Impact of $\alpha$ on $t_{2}^{*}-\widehat{t}_{1}$

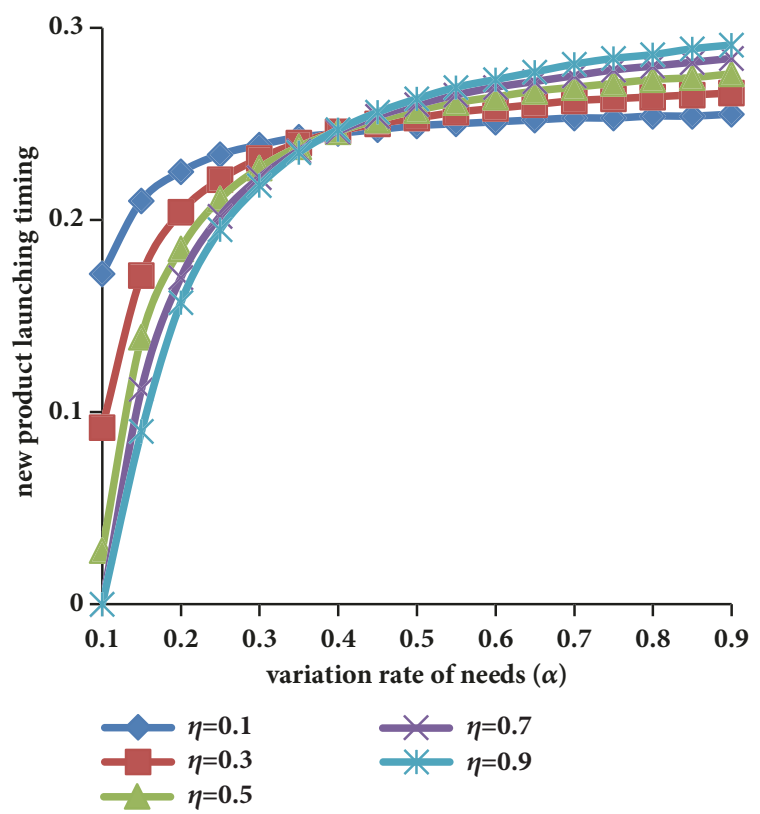

(b) Impact of $\alpha$ on $t_{2}^{*}$

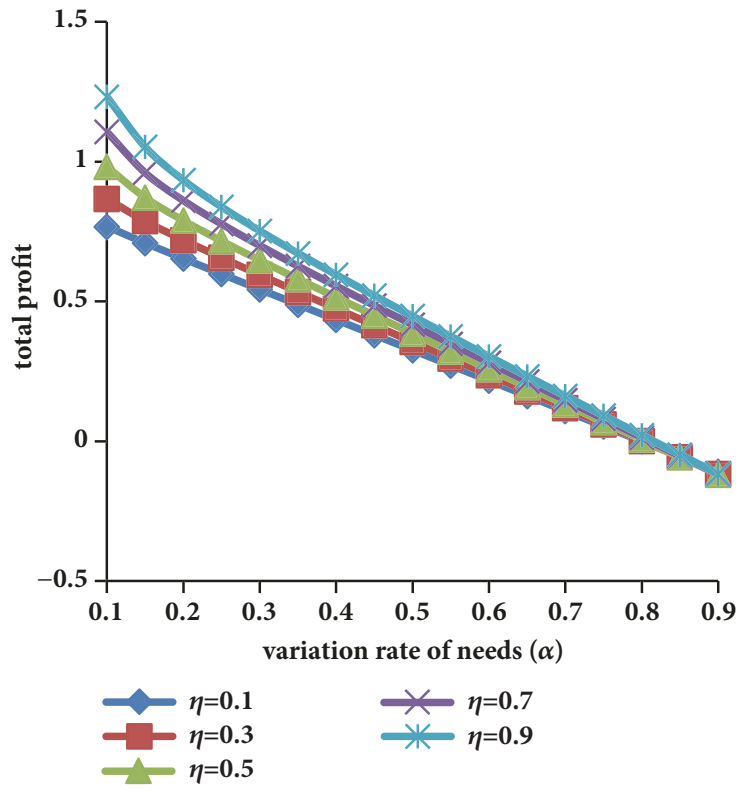

(c) Impact of $\alpha$ on $\pi^{*}$

Figure 8

extended work will lead to the situation of determining the optimal launching timing of different editions of one product generation in addition to planning sequential generations.

Second, the model can be further extended to examine a duopoly setting with two digital product vendors. In this case, economic considerations can be made interdependent across two providers. In a competitive market, firm decisions are affected by new factors, such as consumer switching cost, as investigated by Mehra et al. [19]. The duopoly setting limits the firm's ability to control needs variation but provides new insights into the launching policy of new products from the perspective of competitors and software engineering.

Third, this study can be improved by incorporating development cost. Digital production often involves large upfront costs, and digital product vendors suffer losses if their products do not satisfy consumer needs. Mehra et al. [7] formalize a U-shaped cost model that considers the pros and cons of prolonging the intervals between successive upgrades. The model of [20] incorporates the cost that the consumers incur in customizing the product. Therefore, a rich stream of 


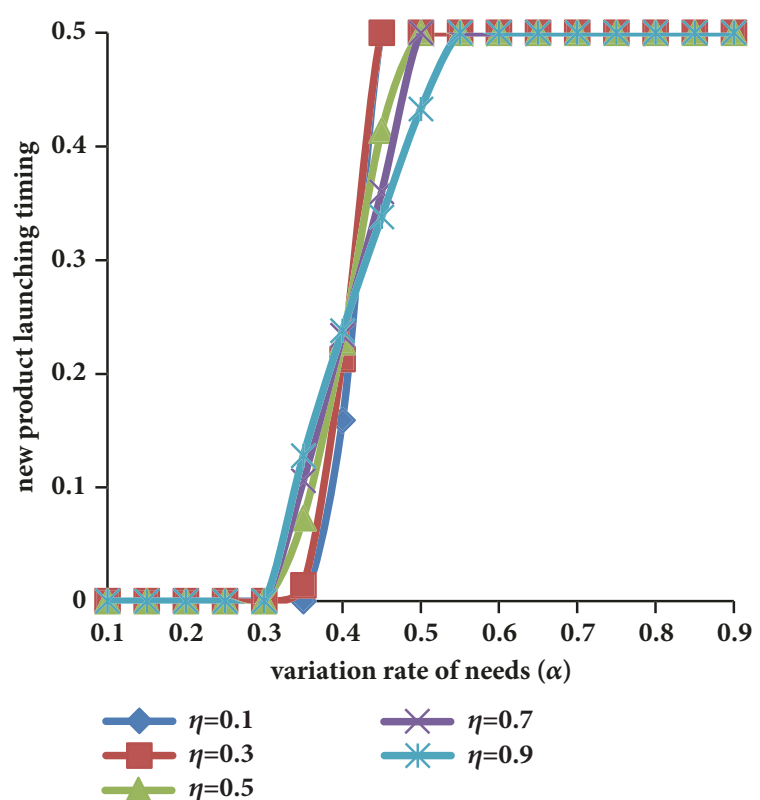

(a) Impact of $\alpha$ on $t_{2}^{*}$

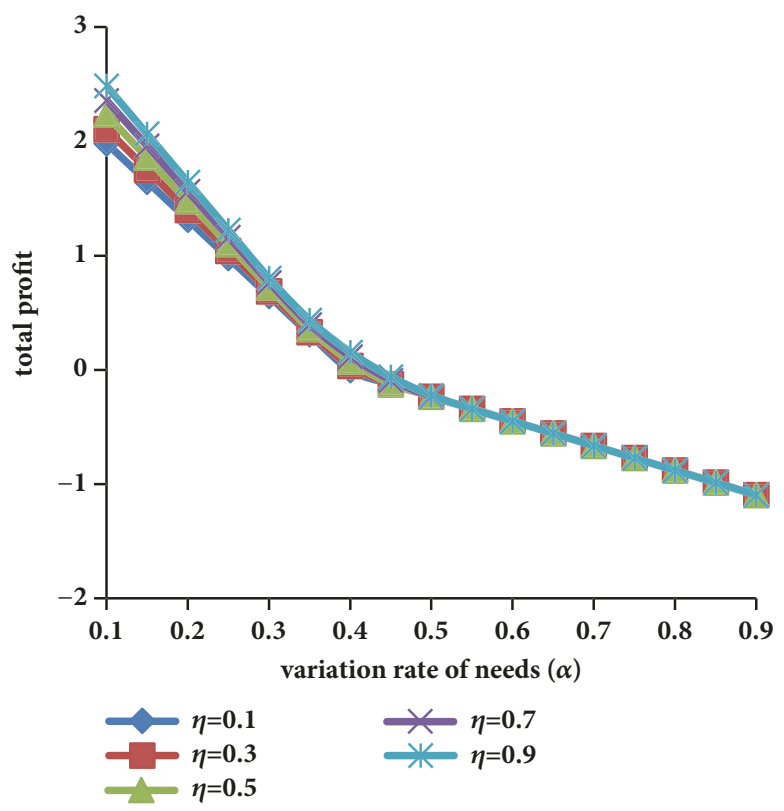

(b) Impact of $\alpha$ on $\pi^{*}$

FIGURE 9

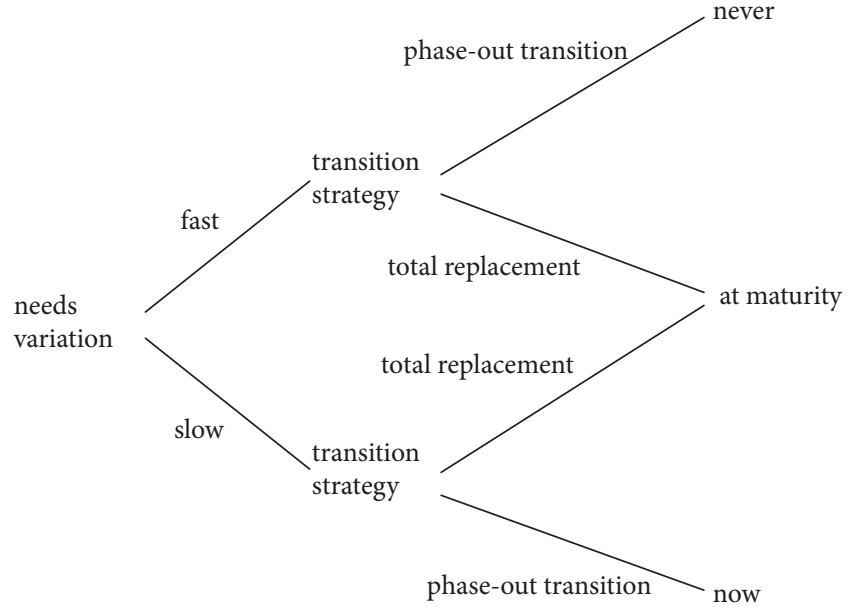

FIGURE 10: Summary of the key conclusions.

further studies is made available by modeling digital product development cost.

Finally, the proposed model can be extended by incorporating network externality that is considered a significant feature of information products [21]. This feature has been studied in previous literature. For example, Dou et al. [22] address the issues that how the digital product firms adjust the strength of network externality to optimize the business model. Therefore, incorporating the network effect is a viable avenue to improve our current model.

\section{Data Availability}

The experiments of the current manuscript are discrete numerical experiments. The value of the parameters is determined stochastically and stated in the manuscript. The results derived from the discrete experiments are available although they are not listed in the manuscript. If the readers need the data of experiments, please do not hesitate to contact the corresponding author.

\section{Conflicts of Interest}

The authors declare that they have no conflicts of interest.

\section{Acknowledgments}

The current paper is supported by (1) National Social Science Foundation of China (no. 16BJY123); (2) Soft Science Research Program Project of Hebei Province (no. 16450124); (3) Research Foundation Program of Hebei University of Economics and Business (no. 2017KYY01).

\section{References}

[1] S. Kalish and G. L. Lilien, "A Market Entry Timing Model for New Technologies," Management Science, vol. 32, no. 2, pp. $194-$ 205, 1986.

[2] Z. Jiang and D. C. Jain, "A generalized Norton-Bass model for multigeneration diffusion," Management Science, vol. 58, no. 10, pp. 1887-1897, 2012.

[3] Z. Jiang, D. C. Jain, and S. Jiang, "Now or never revisited: an analysis of market entry timing for successive product generation," 2015, http://aisel.aisnet.org/amcis2015/AdoptionofIT/ GeneralPresentations/48/.

[4] I. Lobel, J. Patel, G. Vulcano, and J. Zhang, "Optimizing product launches in the presence of strategic consumers," Management Science, vol. 62, no. 6, pp. 1778-1799, 2016.

[5] T. Ebina, N. Matsushima, and D. Shimizu, "Product differentiation and entry timing in a continuous time spatial competition 
model," European Journal of Operational Research, vol. 247, no. 3, Article ID 13056, pp. 904-913, 2015.

[6] V. Choudhary and Z. J. Zhang, "Research note-patching the cloud: the impact of saas on patching strategy and the timing of software release," Information Systems Research, vol. 26, no. 4, pp. 845-858, 2015.

[7] A. Mehra, A. Seidmann, and P. Mojumder, "Product life-cycle management of packaged software," Production Engineering Research and Development, vol. 23, no. 3, pp. 366-378, 2014.

[8] H. K. Bhargava, B. C. Kim, and D. Sun, "Commercialization of platform technologies: Launch timing and versioning strategy," Production Engineering Research and Development, vol. 22, no. 6, pp. 1374-1388, 2013.

[9] L. O. Wilson and J. A. Norton, "Optimal entry timing for a product line extension," Marketing Science, vol. 8, no. 1, pp. 117, 1989.

[10] V. Mahajan and E. Muller, "Timing, diffusion, and substitution of successive generations of technological innovations: the IBM mainframe case," Technological Forecasting \& Social Change, vol. 51, no. 2, pp. 109-132, 1996.

[11] Y. V. Joshi, D. J. Reibstein, and Z. J. Zhang, "Optimal entry timing in markets with social influence," Management Science, vol. 55, no. 6, pp. 926-939, 2009.

[12] R. M. Krankel, I. Duenyas, and R. Kapuscinski, “Timing successive product introductions with demand diffusion and stochastic technology improvement," Manufacturing and Service Operations Management, vol. 8, no. 2, pp. 119-135, 2006.

[13] Y. Dou, Y. J. Hu, and D. J. Wu, "Selling or leasing? Pricing information goods with depreciation of consumer valuation," Information Systems Research, vol. 28, no. 3, pp. 585-602, 2017.

[14] H. Varian, Intermediate Microeconomics: A Modern Approach, vol. 463, Elsevier, 2010.

[15] J. A. Norton and F. M. Bass, "A diffusion theory model of adoption and substitution for successive generations of hightechnology products," Management Science, vol. 33, pp. 10691086, 1987.

[16] F. Bass, "A new product growth model for consumer durables," Management Science, vol. 15, pp. 215-227, 1969.

[17] H. Varian, "Versioning information goods," Working paper of Berkeley, pp. 23-25, 1997, https://www-inst.cs.berkeley.edu/ eecsba1/sp97/reports/eecsbalb/Final/version.pdf.

[18] A. Ando and F. Brayton, "Prices, Wages, and Employment in the U.S. Economy: A Traditional Model and Tests of Some Alternatives," National Bureau of Economic Research w4568, 1993.

[19] A. Mehra, R. Bala, and R. Sankaranarayanan, "Competitive behavior-based price discrimination for software upgrades," Information Systems Research, vol. 23, no. 1, pp. 60-74, 2012.

[20] Z. Gu and G. K. Tayi, "Investigating firm strategies on offering consumer-customizable products," Information Systems Research, vol. 26, no. 2, pp. 456-468, 2015.

[21] H. K. Cheng, S. Li, and Y. Liu, "Optimal software free trial strategy: limited version, time-locked, or hybrid?” Production Engineering Research and Development, vol. 24, no. 3, pp. 504517, 2015.

[22] Y. Dou, M. F. Niculescu, and D. J. Wu, "Engineering optimal network effects via social media features and seeding in markets for digital goods and services," Information Systems Research, vol. 24, no. 1, pp. 164-185, 2013. 


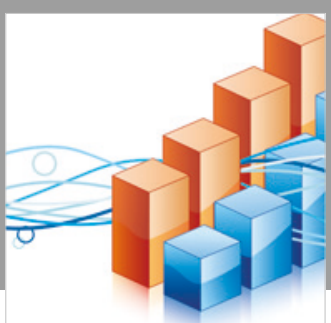

Advances in

Operations Research

\section{-n-m}
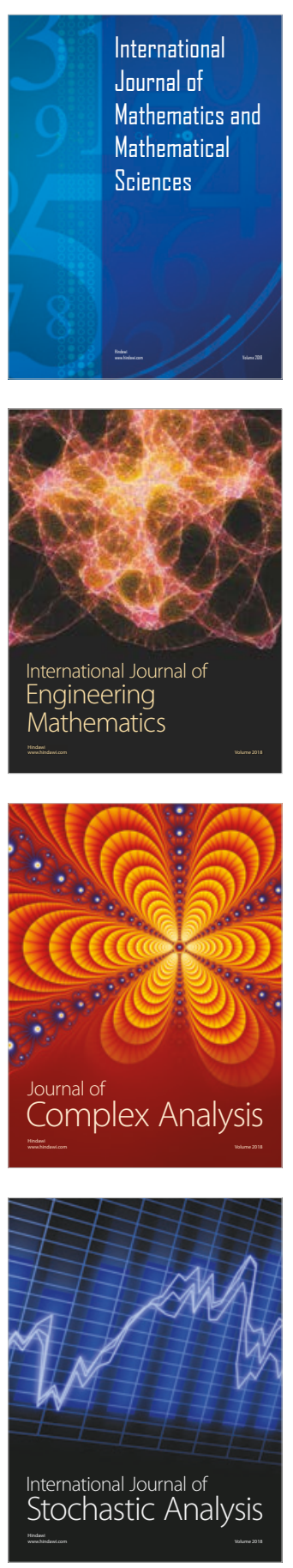
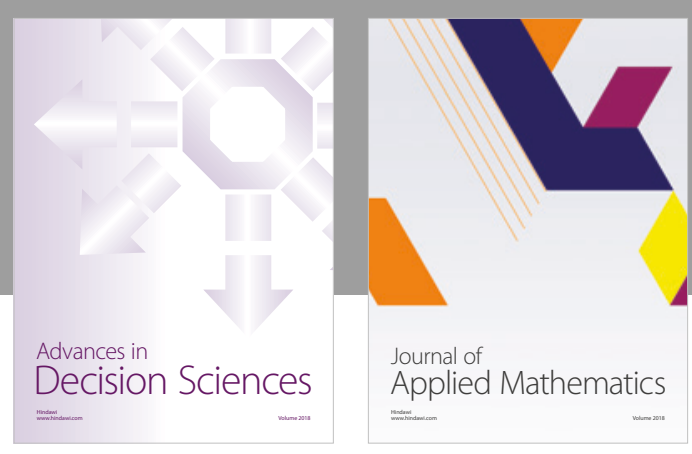

Journal of

Applied Mathematics
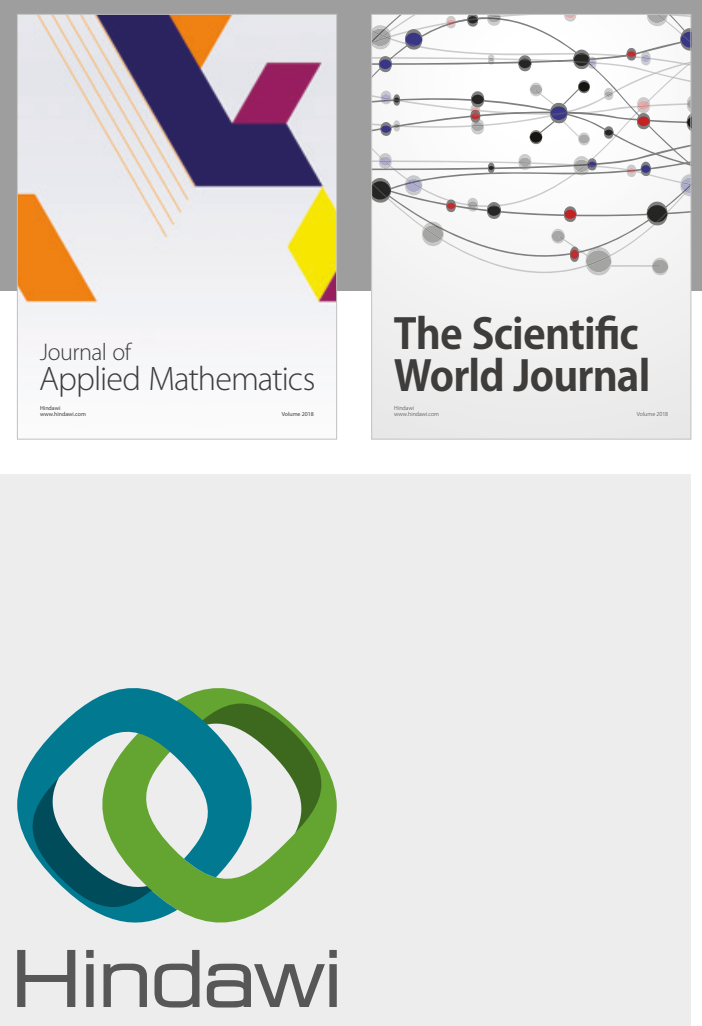

Submit your manuscripts at

www.hindawi.com

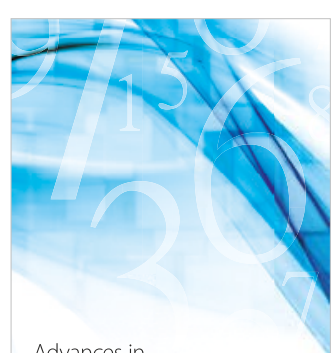

Advances in
Numerical Analysis
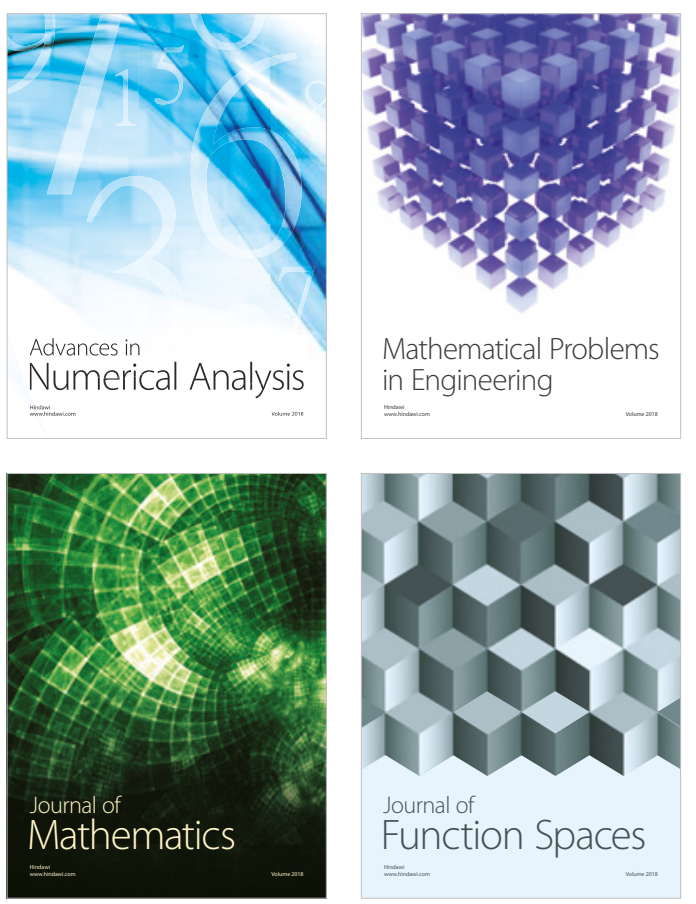

Mathematical Problems in Engineering

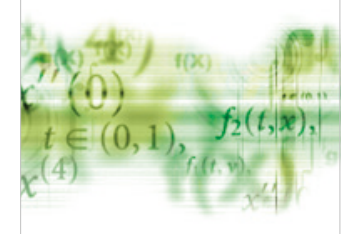

International Journal of

Differential Equations

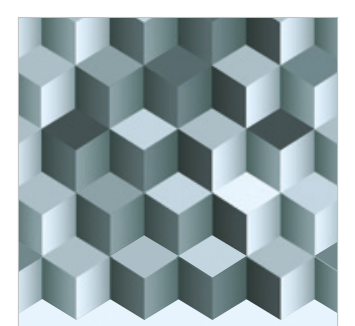

Journal of

Function Spaces

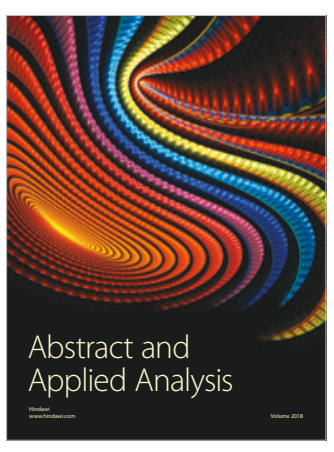

The Scientific

World Journal

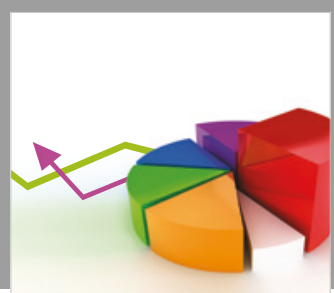

Journal of

Probability and Statistics
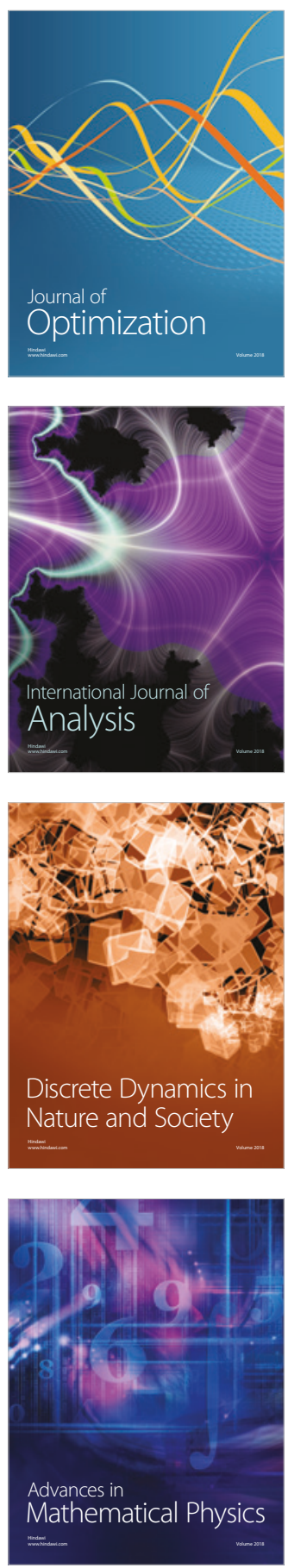